\title{
Sistem Keamanan Sepeda Motor Berbasis Internet of Things
}

\author{
Ikhsan ${ }^{1}$, Elfizon ${ }^{2}$ \\ ${ }^{1}$ Univeritas Negeri Padang \\ Jl. Prof Dr. Hamka Air Tawar, Padang Indonesia \\ M.ikhsan31@gmail.com,Elfizon24@gmail.com
}

\begin{abstract}
Along with the times, the human need for means of transportation is increasing, one of which is motorbikes. The problem that often occurs at this time is the case of motorcycle theft, which often occurs due to lack of security systems. Therefore, this study will discuss the Internet of Things-Based Motorcycle Security System which aims to secure motorbikes from theft and this tool can also send the coordinates of the motorbike to see where the motorcycle is. This research consists of hardware which includes Arduino Nano, RFID Tag, RFID Reader, ESP8266 Module, Accelerometer Sensor, GPS, Relay, and Buzzer and Arduino IDE coding system software. After conducting several experiments in this study the system was able to work in accordance with the research objectives. The research in this final project can make it easier for motorcycle owners to find the whereabouts of a motorcycle in the event of a theft case.
\end{abstract}

Keywords-RFID Tag, RFID Reader, GPS, Sensor Accelerometer, Modul ESP8266, Relay, Buzzer, Arduino Nano.

Abstrak- Seiring dengan perkembangan zaman, maka kebutuhan manusia akan alat transportasi semakin meningkat, salah satunya yaitu sepeda motor. Permasalahan yang sering terjadi pada saat ini adalah kasus pencurian sepeda motor yang seringkali terjadi dikarenakan masih kurangnya sistem keamanan. Oleh karena itu, penelitian ini akan membahas Sistem Keamanan Sepeda Motor Berbasis Internet of Things yang bertujuan untuk mengamankan sepeda motor dari tindakan pencurian dan alat ini juga dapat mengirimkan koordinat sepeda motor tersebut untuk melihat dimana keberadaan sepeda motor tesebut. Penelitian ini terdiri dari perangkat keras (hardware) yang meliputi Arduino Nano, RFID Tag, RFID Reader, Modul ESP8266, Sensor Accelerometer, GPS, Relay, serta Buzzer dan perangkat lunak (software) Arduino IDE pengkodean sistem. Setelah melakukan beberapa percobaan pada penelitian ini sistem mampu bekerja sesuai dengan tujuan peneitian. Penelitian pada tugas akhir ini dapat mempermudah pemilik sepeda motor mencari keberadaan sepeda motor apabila terjadi kasus pencurian.

Kata kunci-RFID Tag, RFID Reader, GPS, Sensor Accelerometer, Modul ESP8266, Relay, Buzzer, Arduino Nano.

\section{PENDAHULUAN}

Sepeda motor merupakan alat transportasi yang penting bagi masyarakat Indonesia dikarenakan harganya yang sangat tejangkau bagi masyarakat yang ekonominya menengah kebawah. Sepeda motor juga merupakan alternatif terbaik bagi masyarakat yang ingin terhindar dari padat dan macetnya dijalan raya[1]. Alasan yang sering digunakan dalam penggunaan sepeda motor adalah karena harga yang terjangkau dan hemat bahan bakar. Seiring dengan perkembangan zaman, maka kebutuhan manusia akan alat transportasi semakin meningkat, salah satunya yaitu sepeda motor. Perkembangan ini juga mempengaruhi tindak kriminalitas yang akan ikut meningkat, seperti kasus pencurian sepeda motor. Kasus pencurian ini masih seringkali terjadi dikarenakan masih kurangnya sistem keamanan yang terdapat pada sepeda motor.

Banyaknya kasus pencurian yang terjadi pasti membuat pengguna kendaraan bermotor khawatir, alat keamanan yang standar seperti kunci kontak motor variasi, kunci gembok, kunci kontak saja belum tentu menjamin keamanan sepeda motor kita[2]. Tindak pidana pencurian kendaraan bermotor di Indonesia setiap tahunnya semakin meningkat. Demikian halnya di Polres Gowa, pencurian kendaraan bermotor semakin meningkat. Berdasarkan data bagian operasi Polres Gowa dari rentan waktu tahun 2010 sejumlah 36 kasus, pada tahun 2011 sejumlah 68 kasus, tahun 2012 sejumlah 144 kasus, dan pada tahun 2013 (Januari-April) 77 kasus[3]. Banyaknya kasus pencurian sepeda motor yang sering terjadi membuat penulis ingin menuangkan ide serta gagasan sebagai solusi untuk mengatasi permasalahan tersebut, salah satu nya adalah dengan cara merancang Penerapan Internet of Thing dalam Perancangan Aplikasi Pengaman Sepeda Motor Berbasis Android.

Berdasarkan masalah serta batasan masalah maka penulis akan membahas proyek akhir ini yaitu bagaimana merancang alat sistem keamanan sepeda motor menggunakan Internet of Things (IoT). Salah satu solusi untuk mengamanakan sepeda motor dari tindakan pencurian adalah menerapkan teknologi sistem keamanan cerdas (intelligent security system) dengan menggabungkan teknologi IoT (Internet of Things) tergolong sebagai teknologi pengamann di masa depan. Kehadiran teknologi ini perlu terus diupayakan dan 
dikembangkan agar sampai ke ranah industri, sehingga manfaatnya dapat dirasakan oleh masyarakat. Maanfat nyata adanya teknologi ini adalah semakin efektif dan efiesian untuk keamanan sepeda motor[4]. Internet of Things (IoT) pertama kali diperkenalkan oleh Kevin Ashton pada tahun 1999. Meski ini telah diperkenalkan sejak 15 tahun yang lalu, hingga saat ini belum ada sebuah konsensus global mengenai definisi IoT. Namun secara umum konsep Internet of Things diartikan sebagai sebuah kemampuan untuk menghubungkan objek-objek cerdas dan memungkinkan untuk berinteraksi dengan objek lain, seperti lingkungan maupun dengan peralatan komputasi cerdas lainnya melalui jaringan internet. Internet of Things dalam berbagai bentuknya telah mulai diaplikasikan pada banyak aspek kehidupan manusia.

Internet of Things (IoT) memungkinkan pengguna untuk mengelola dan mengoptimalkan peralatan elektronik yang menggunakan internet. Hal ini berspekulasi bahwa di sebagian waktu dekat komunikasi antara komputer dan peralatan elektronik mampu bertukar informasi di antara mereka sehingga mengurangi interaksi manusia. Hal ini juga dapat membuat pengguna internet semakin meningkat dengan berbagai fasilitas dan layanan internet. Untuk mengetahui suatu keberadaan sepeda motor kita perlu adanya Smartphone Android agar kita bisa melacak kendaraan menggunakan google maps nantinya. Disini kita juga menggunakan Aplikasi WhatsApp sebagai pemberitahuan bahwa sepeda motor kita sedang berada di dalam posisi tidak aman. Aplikasi biasanya berupa perangkat lunak yang berbentuk software yang berisi kesatuan perintah atau program yang dibuat untuk melaksanakan sebuah pekerjaan yang diinginkan.

\section{METODE}

Metode yang digunakan dalam penelitian ini adalah membuat sistem keamanan sepeda motor berasis Internet of Things

\section{A. Blok Diagram}

Langkah selanjutnya pada perancangan adalah membuat suatu blok diagram sebagai acuan dimana setiap blok mempunyai fungsi tertentu dan saling terkait sehingga membentuk system dari alat yang dibuat. Proses perancangan dan pembuatan alat dibagi dalam dua tahap yaitu perancangan bagian hardware (perangkat keras), perancangan software (perangkat lunak).

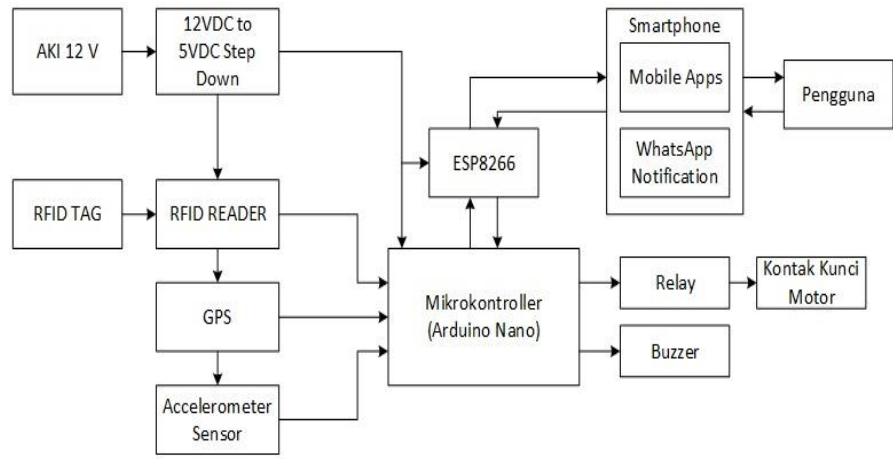

Gambar 1. Blok Diagram

Pada blok diagram diatas dijelaskan sebagai berikut:

1. RFID tag berfungsi sebagai kunci elektronik yang akan dijadikan identitas pengguna kendaraan.

2. RFID reader berfungsi untuk men-scan ID yang tertanam dalam RFID tag.

3. GPS (Global Positioning System) berfungsi untuk melacak posisi kendaraan. Output dari GPS ialah berupa titik koordinat Latitude dan Longitude bumi.

4. Sensor Accelerometer ADXL345 berfungsi untuk mendeteksi adanya getaran, hal ini bertujuan untuk mengetahui apakah ada aktifitas yang mencurigakan yang terjadi pada motor.

5. Mikrokontroler ATMega328 (Arduino Nano) berfungsi menerima perintah dari pengguna melalui aplikasi smartphone yang dikirimkan melalui jaringan internet dengan bantuan modul ESP 8266, membaca ID yang telah di scan oleh RFID reader, menerima data dari GPS, dimana selanjutnya data tersebut akan diproses oleh arduino dan keluaran dari arduino ini akan memberikan perintah untuk mengontrol relay, dan buzzer sebagai alarm.

6. Modul ESP 8266 berfungsi sebagai media penerima data dari aplikasi di smartphone yang dikirimkan melalui internet dan juga sebagai media pengiriman data dari alat ke smartphone pengguna.

7. Relay berfungsi sebagai saklar elektromagnetik agar bisa mengontrol on dan off sepeda motor.

8. Smartphone berfungsi sebagai pengontrol dan monitoring sepeda motor dari jarak jauh melalui jaringan internet.

9. Aplikasi WhatsApp berfungsi sebagai penerima notifikasi bahwa kendaraan sepeda motor kita sedang berada diposisi tidak aman. 


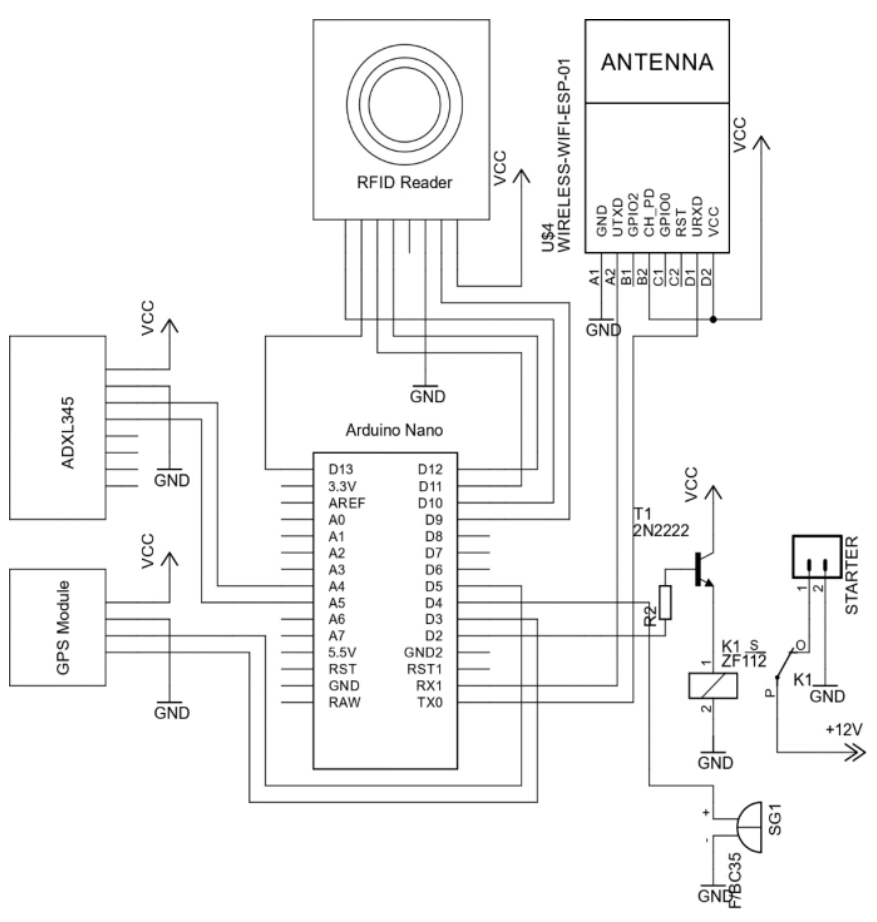

Gambar 2. Rangkaian Keseluruhan

\section{B. Flowchart}

Cara kerja alat ini dilakukan melalui suatu bagan yang menunjukkan urutan suatu program. Flowchart tsistem keamanan sepeda motor berasis Internet of Things dapat dilihat pada gambar 3.

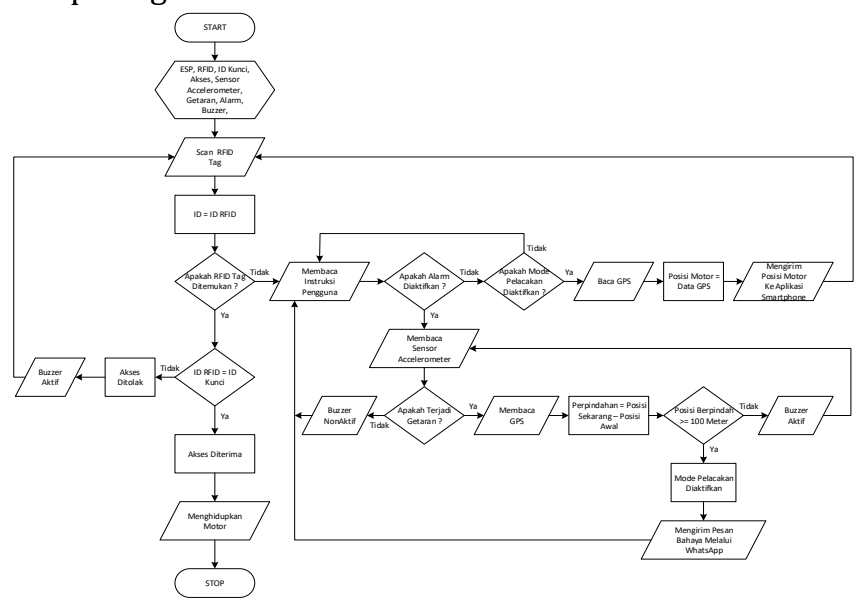

Gambar 3. Flowchart

Pada gambar 3 diatas merupakan flowchart atau diagram alir cara kerja alat secara keseluruhan , sistem diawali dengan inisialisasi port, kemudian sistem akan mendeteksi masing-masing keadaan.

\section{Perancangan Hardware}

Peracangan mekanik merupakan suatu proses atau tahapaan dalam pembuatan tugas akhir ini. Perancangan ini bertujuan mengurangi kesalahan serta agar memudahkan dalam membuat alat sehingga mendapatkan hasil yang maksimal.

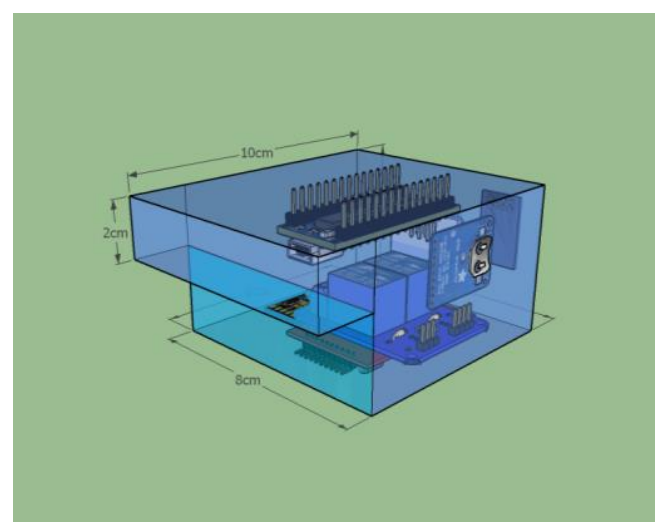

Gambar 4. Bentuk rancangan alat

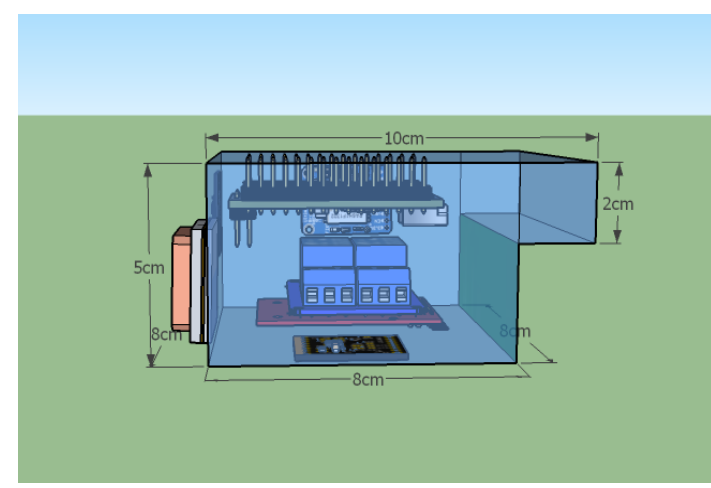

Gambar 5. Alat tampak samping

\section{Perancangan Software}

Perancangan software secara keseluruhan pada tugas akhir ini menggunakan Arduino IDE, yaitu software yang merupakan bawaan dari arduino itu sendiri, sehingga dapat mengendalikan seluruh input dan output yang digunakan pada sistem sistem keamanan sepeda motor ini. Pada software Arduino IDE dapat dilakukan proses compile dan upload program yang dibuat ke dalam mikrokontroler arduino. Kode - kode program arduino dibuat menggunakan bahasa pemrograman $\mathrm{C}$.

\section{III.HASIL DAN PEMBAHASAN}

Pada hasil dan pembahasan ini akan dilakukan beberapa pengujian dan analisa pada seluruh bagian input maupun output. Pengujian dan analisa ini dilakukan untuk mengetahui apakah sensor berfungsi dengan baik sebagai input sesuai dengan yang direncanakan

\section{Pengujian Alarm/Buzzer}

Buzzer yang digunakan adalah buzzer jenis umum dengan supply tegangan input maksimal 5V. Untuk melakukan pengujiam pada buzzer maka terlwbih dahulu membuat script program, lalu di upload-kan ke board Arduino. 
Tabel I. Pengujian Buzzer

\begin{tabular}{|c|c|c|c|}
\hline No & Jenis Pengujian & $\begin{array}{c}\mathrm{V} \\
\text { Terukur }\end{array}$ & $\begin{array}{c}\text { Kondisi } \\
\text { Buzzer }\end{array}$ \\
\hline 1 & $\begin{array}{c}\text { Pengujian pada logika } \\
0\end{array}$ & $0 \mathrm{~V}$ & Off \\
\hline 2 & $\begin{array}{c}\text { Pengujian pada logika } \\
1\end{array}$ & $3,86 \mathrm{~V}$ & On \\
\hline
\end{tabular}

Berdasarkan dari hasil pengukuran buzzer ini menghasilkan tegangan output sebebsar 3,86V, maka hasil tegangan output tersebut dapat dijalankan karena masih dalam rentang kerja, serta besar suara yang dikeluarkan oleh alat dapat terdengar sampai jarak >= 8 meter.

\section{Pengujian Notifikasi WhatsApp di Smartphone}

Di perancangan sistem ini juga digunakan sebuah notifikasi yang menandakan bahwa telah terjadinya gangguan terhadap sepeda motor, dimana aplikasi yang digunakan adalah aplikasi android yaitu WhatsApp. Untuk hasil pengujian notifikasi ini dapat dilihat pada tabel 2 dibawah ini.

Tabe II. Pengujian notifikasi WhatsApp di Smartphone

\begin{tabular}{|c|c|c|c|c|}
\hline ID & Nama & No WhatsApp & Status & $\begin{array}{c}\text { Wakt } \\
\mathrm{u}\end{array}$ \\
\hline 24 & $\begin{array}{c}\text { Marta } \\
\text { Zuriadi }\end{array}$ & 6281372267162 & $\begin{array}{c}\text { Terkiri } \\
\mathrm{m}\end{array}$ & $\begin{array}{c}5 \\
\text { Sekon }\end{array}$ \\
\hline 25 & $\begin{array}{c}\text { Indra } \\
\text { maidoni }\end{array}$ & 6282169073657 & $\begin{array}{c}\text { Terkiri } \\
\mathrm{m}\end{array}$ & $\begin{array}{c}3 \\
\text { Sekon }\end{array}$ \\
\hline 25 & Ikhsan & 6285357697428 & $\begin{array}{c}\text { Terkiri } \\
\mathrm{m}\end{array}$ & $\begin{array}{c}6 \\
\text { Sekon }\end{array}$ \\
\hline 27 & Aulia Novira & 6282386607513 & $\begin{array}{c}\text { Terkiri } \\
\mathrm{m}\end{array}$ & $\begin{array}{c}7 \\
\text { Sekon }\end{array}$ \\
\hline 28 & $\begin{array}{c}\text { Keke } \\
\text { wahyuni }\end{array}$ & 6282180880307 & $\begin{array}{c}\text { Terkiri } \\
\mathrm{m}\end{array}$ & $\begin{array}{c}5 \\
\text { Sekon }\end{array}$ \\
\hline \multicolumn{4}{|c|}{ Rata-rata } & $\begin{array}{c}5,67 \\
\text { Sekon }\end{array}$ \\
\hline
\end{tabular}

Berdasarkan table diatas aplikasi notifikasi WhatsApp, diamana pengujian dilakukan menggunakan nomor dengan bergantian untuk mengetahui seberapa efektif pengiriman notifikasi melalui aplikasi WhatsApp dan mengetahui berapa lama rata-rata waktu sistem mengirim notifikasi ke apliksai WhatsApp.

\section{Pengujian MIT App Invertor di Smartphone}

Fungsi paling dasar adalah unntuk memantau posisi kendaraan secara real time, tidak ada pengaruh soal jarak antara motor dan pemilik. Contohnya, saat motor ditinggal atau motor sedang digunakan orang lain.
Tabel III. Pengujian MIT App Invertor di Smartphone

\begin{tabular}{|c|c|c|c|}
\hline \multirow{2}{*}{ No } & \multirow{2}{*}{ Jarak $(\mathrm{Km})$} & \multicolumn{2}{|c|}{ Kondisi Sepeda Motor } \\
\cline { 3 - 4 } & 1 & Hidupkan & Matikan \\
\hline 1 & 2 & ON & OFF \\
\hline 2 & 4 & ON & OFF \\
\hline 3 & 6 & ON & OFF \\
\hline 4 & 8 & ON & OFF \\
\hline 5 & & ON & OFF \\
\hline
\end{tabular}

Tabel IV. Pelacakan kendaraan menggunakan MIT App Invertor

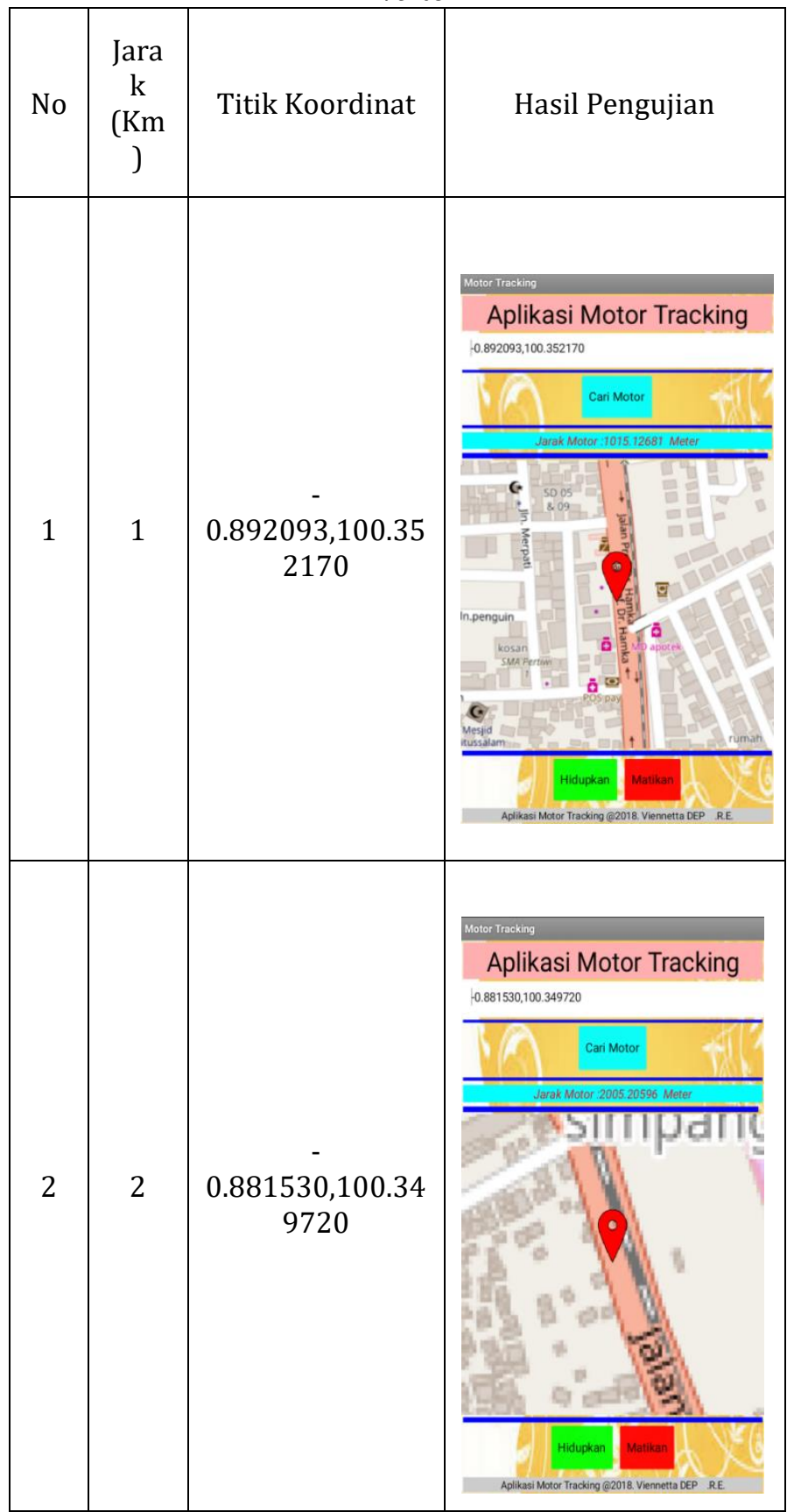




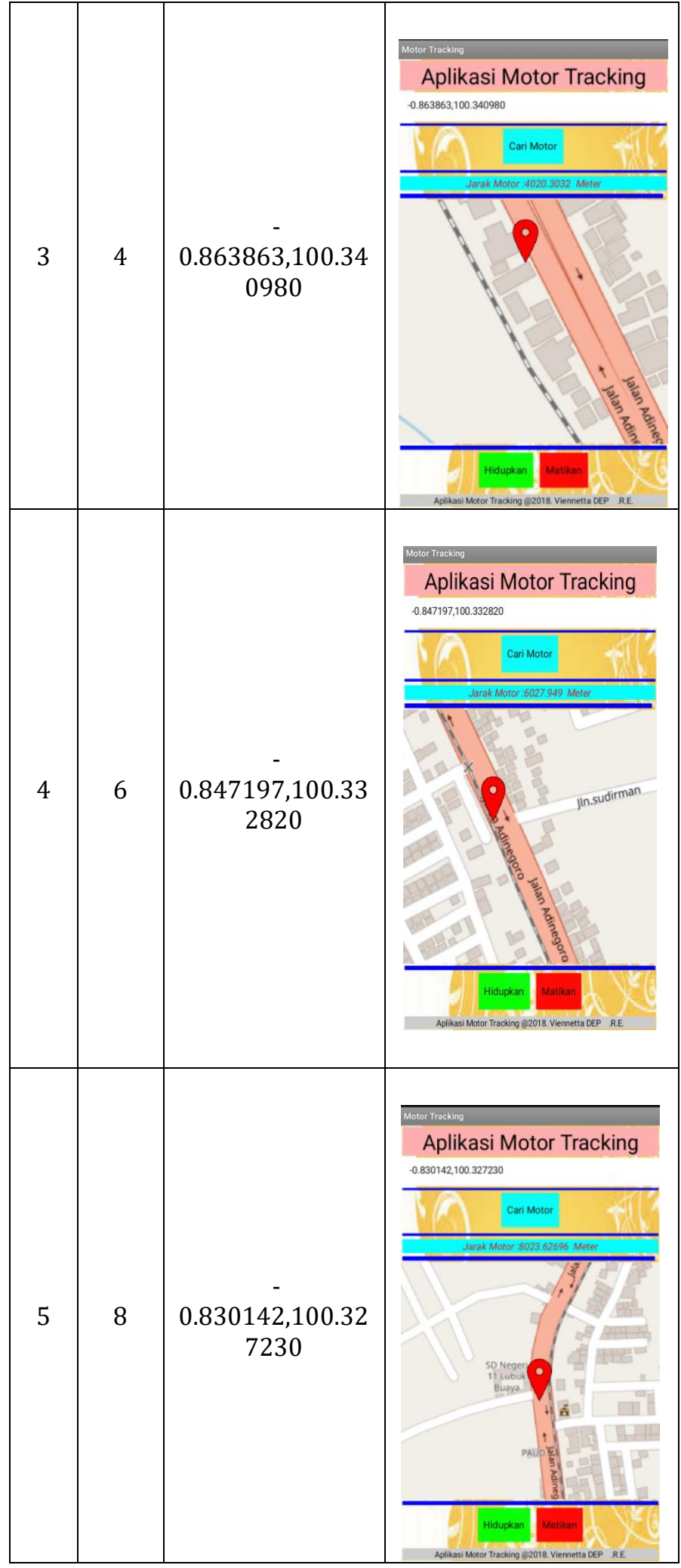

Dari hasil pengujian pada android, dalam jarak maksimal pengujian yang dilakukan sejauh $8 \mathrm{Km}$ dapat merespon dan mengirim notifikasi dari sistem untuk melakukan eksekusi dan mengirim koordinat letak posisi sepeda motor yang sebenarnya kurang dari waktu yang disetting (10 detik) baik untuk mematikan sepeda motor, menghidupkan sepeda motor, mendapaatkan koordianat yang real.

Pada prinsipnya, tugas akhir ini berfungsi sebagai pelacakan dan mendapatkan koordinat untuk mengetahui lokasi dimana letak sepeda motor.

\section{Pengujian alat secara keseluruhan}

Adapun tujuan pengujian ini untuk melihat sejauh mana hasil dari kerja alat sistem sistem keamanan sepeda motor ini, sehingga didapatkan hasil dan perbandingan dari apa yang direncanakan sebelumnya. Pada tahap ini, alat akan dioperasikan secara normal dengan menghubungkan ke kontak listrik. Pengujian alat secara keseluruhan dapat dilihat pada tabel 5

Tabel V. Pengujian Alat Keseluruhan

\begin{tabular}{|c|c|c|c|c|}
\hline No & $\begin{array}{c}\text { Nama } \\
\text { Komponen }\end{array}$ & $\begin{array}{l}\text { Berfungs } \\
\text { i }\end{array}$ & $\begin{array}{c}\text { Tidak } \\
\text { Berfungsi }\end{array}$ & Keterangan \\
\hline 1 & RFID Reader & $\sqrt{ }$ & 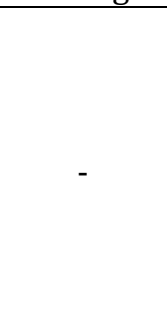 & $\begin{array}{l}\text { Berfungsi } \\
\text { sebagai } \\
\text { kunci } \\
\text { elektronik } \\
\text { yang akan } \\
\text { dijadikan } \\
\text { identitas } \\
\text { pengguna }\end{array}$ \\
\hline 2 & RFID Tag & $\sqrt{ }$ & - & $\begin{array}{l}\text { Berfungsi } \\
\text { untuk men- } \\
\text { scan ID } \\
\text { yang } \\
\text { tertanam } \\
\text { dalam RFID } \\
\text { tag. }\end{array}$ \\
\hline 3 & GPS & $\sqrt{ }$ & - & $\begin{array}{l}\text { Berfungsi } \\
\text { untuk } \\
\text { melacakak } \\
\text { kendaraan }\end{array}$ \\
\hline 4 & $\begin{array}{l}\text { Sensor } \\
\text { Accelerometer }\end{array}$ & $\sqrt{ }$ & - & $\begin{array}{l}\text { Berfungsi } \\
\text { untuk } \\
\text { mendeteksi } \\
\text { adanya } \\
\text { getaran }\end{array}$ \\
\hline 5 & Relay & $\sqrt{ }$ & - & $\begin{array}{l}\text { Berfungsi } \\
\text { sebegai } \\
\text { saklar } \\
\text { elektromag } \\
\text { netik }\end{array}$ \\
\hline 6 & Buzzer & $\sqrt{ }$ & - & $\begin{array}{l}\text { Berfungsi } \\
\text { sebagai } \\
\text { alarm }\end{array}$ \\
\hline
\end{tabular}




\section{IV.PENUTUP}

Berdasarkan hasil pengujian dan analisa yang telah dilakukukan terhadap alat sistem keamanan sepeda motor berbasis Internet of Things, maka dapat diperoleh kesimpulan jika sepeda motor diangkat secara paksa, maka sistem sensor GPS yang terdapat di sepada motor tersebut akan mengirimkan titik koordinat ke aplikasi yang ada di android untuk pelacakan dan jika android tidak bisa digunakan dengan alasan tertentu ataupun pengguna tidak sadar saat sepeda motor telah dihidupkan, maka sistem manual efektif mengantisipasi keadaan tersebut.

\section{REFERENSI}

[1] N. Effendi, A. Jefiza, and F. Okmayura, "Sistem Kendali Cerdas Untuk Keamanan Sepeda Motor Berbasis Android," pp. 61-72, 2018.

[2] F. Sudarto and D. Ramdani, "Sistem Keamanan Menggunakan Mikrokontroler AT89S52 Berbasis SMS Sebagai Cara Baru Mengatasi Pencurian Sepeda Motor," pp. 71-80, 2012.

[3] E. P. Police, "Tinjauan kriminologi pencurian sepeda motor di wilayah polsek palu timur," no. 1, pp. 1594-1600, 2013.

[4] D. Widiyanto and S. Sulasmingsih, "Purwa Rupa Sistem Pengaman Sepeda Motor Berbasis IoT ( Internet of Things )," vol. 11, no. 1, pp. 49-57, 2019.

[5] Andesta, D., \& Ferdian, R. "Sistem Keamanan Sepeda Motor Berbasis Mikrokontroler dan Modul GSM. 02, 51-63, 2018.

[6] Sujadi, H., \& Paisal, P. "Sistem Keamanan Sepeda Motor Menggunakan Mikrokontroller Arduino Uno R3 Dengan Sensor HC-SR501 dan HC-SR04”. IV(2), 125-130,2018.

[7] Prasetya, D. I., \& Supomo, J. P. "Sistem Keamanan Sepeda Motor Menggunakan Kata Sandi Berbasis Arduino Nano". 4(1). 2018.

[8] Junus, M. "Sistem Pelacakan Posisi Kendaraan Dengan Teknologi GPS \& GPRS Berbasis Web". 10(02), 58-67, 2012.

[9] Juwariyah, T., Dewi, A. C., Studi, P., Industri, T., \& Selatan, J. "Rancang Bangun Sistem Keamanan Sepeda Motor". 13, 223-227, 2017.

[10] H. Muchtar and B. Firdaus, "Kendaraan Sepeda Motor Berbasis Aplikasi Android," pp. 1-2, 2017.

\section{Biodata Penulis}

Ikhsan , lahir di Lolo Gedang, 11 April 1998, sedang menyelesaikan Program studi DIV Teknik Elektro Industri pada Jurusan Teknik Elektro Fakultas Teknik Universitas Negeri Padang.

Elfizon, S.Pd, M.Pd.T , lahir di Lima Puluh Kota, 25 Agustus 1985, menyelesaikan S1 di Universitas Negeri Padang dan S2 di Universitas Negeri Padang, Staf pengajar tetap di Jurusan Teknik Elektro Fakultas Teknik Universitas Negeri Padang sampai sekarang. 